\title{
La perspectiva de género en las prácticas deportivas: hacia una visión coeducativa en educación física
}

\section{The gender perspective in sports activities: towards a co- educational view of physical education}

DOI: https://doi.org/10.32870/dse.v0i20.592

\section{Claudia Ivonne Hernández Ramírez.*}

García Villanueva, J., K.A. Talavera Torres, L.D. Villanueva Chávez y L.A. Gamba Mondragón (2018). Género en la Educación Física: propuestas didácticas. México: UPN.

En la actualidad, los estereotipos relacionados con la actividad física y el deporte persisten en el estudiantado de educación básica, específicamente en primaria y secundaria (Piedra de la Cuadra, García Pérez, Latorre Romero y Quiñones Delgado, 2013). El profesorado que imparte la asignatura de educación física aún continúa llevando a cabo actividades que mantienen una visión binaria del cuerpo femenino y masculino, conservando una carga cultural, simbólica y desigual al considerar la imagen corporal desproporcionada según el género de las personas.

Las estrategias de enseñanza expuestas en el libro: Género en la Educación Física: propuestas didácticas, apelan a las buenas prácticas coeducativas en educación física, como bien mencionan Piedra de la Cuadra, García Pérez, Latorre Romero y Quiñones Delgado (2013), porque buscan propiciar la igualdad entre las mujeres y los hombres, eliminando los estereotipos de género, las acciones sexistas, y pretenden hacer partícipes a las mujeres en el deporte y las actividades físicas.

La obra da a conocer una serie de pautas de intervención para que las personas que se desempeñan como docentes de educación física puedan utilizarlas para realizar su trabajo con perspectiva de género, es decir, lo que se busca es que en la práctica de las actividades físicas y deportivas no se continúe separando al alumnado por sexo, sino que se construyan modos y hábitos que dejen de lado la discriminación, la reproducción de esquemas machistas que miran a los hombres o niños como fuertes, poderosos e invencibles, y a las mujeres o niñas como frágiles, débiles e incapaces (Saraví, 1997).

* Maestría en Desarrollo Educativo. Universidad Pedagógica Nacional. Las líneas de investigación y trabajo giran en torno al estudio del quehacer docente, currículum, la escritura científica, género y educación, feminización en la educación y masculinidades. México. civonneramirez@hotmail.com cihernandez@upn.mx 
Al inicio del libro se destacan los principales fundamentos de la perspectiva de género, la diferencia del sistema sexo-género, las aportaciones del ámbito social y cultural, así como la impronta hacia la igualdad de trato entre las personas. Posteriormente, se explica la relación entre género, educación y políticas públicas; para finalizar se describen las propuestas de enseñanza y las situaciones didácticas con un enfoque de género en cuatro deportes: basquetbol, futbol, voleibol, natación y una actividad deportiva general.

El propósito de que las actividades deportivas estén diseñadas con perspectiva de género es interpelar la propuesta educativa tradicional, cuyos estereotipos de género son vistos como rasgos inherentes a las personas que dictan cómo deben ser las mujeres y los hombres y qué tipo de papeles deben desempeñar en la sociedad, porque dichos estereotipos perpetúan las relaciones de desigualdad, en perjuicio de las mujeres y las minorías sexuales (Khidir y Leonardi, 2017).

La importancia de la impartición de la educación física en las escuelas radica en que el estudiantado debe tener hábitos para llevar una vida saludable que desemboque y propicie un desarrollo personal y social que le sirva para la vida adulta (Gómez Rijo, Gómez Medina y Martínez Herráez, 2011).

No hay que olvidar que, históricamente, el cuerpo ha sido atravesado por distintos dispositivos, prácticas, creencias, saberes, modelos y conceptos que lo han configurado y reconfigurado desde diferentes instituciones y discursos mediante diversas escuelas de pensamiento (López Gutiérrez, Stuart Rivero y Granado Mejías, 2012).

La propuesta pedagógica no representa un manual o sumario de actividades que se deben llevar a cabo en orden estricto, sino una alternativa de trabajo que busca contribuir a la mejora de la labor docente para que se puedan resarcir las desigualdades de trato entre los géneros, se combatan los atavismos patriarcales y sexistas que preservan las entrañas de la misoginia, el machismo y las relaciones de poder.

Intervenir en la clase de educación física con una perspectiva de género implica la construcción de valores, actitudes y formas de socialización que contribuyan al auténtico desarrollo integral de mujeres y hombres, en el marco del reconocimiento y respeto entre las personas para alcanzar la equidad sobre la base de las diferencias (Reinoso Castillo y Hernández Martín, 2011).

\section{Referencias}

Gómez Rijo, A., S. Gómez Medina e I. Martínez Herráez (2011). Efectos del género y la etapa educativa del estudiante sobre la satisfacción y la desmotivación en educación física durante la educación obligatoria. Ágora para la Educación Física y el Deporte, 2(13), 183-196.

Diálo Dos

sobre Educación año 11 | número 20 | enero-junio 2020 | ISSN 2007-2171 
Khidir, A. y Leonardi, M. (2017). La cuestión de género en las clases de Educación Física. Cómo interpela las clases tradicionales. Ponencia, $12^{\circ}$ Congreso Argentino y $7^{\circ}$ Latinoamericano de Educación Física y Ciencias. http://congresoeducacionfisica.fahce.unlp.edu.ar/12ocongreso/120-congreso/actas-2017

López Gutiérrez, C., Stuart Rivero, A. y Granado Mejías, A. (2012). Conocimientos básicos de Educación Física-salud para autogestión de la actividad física. Revista lberoamericana de Educación, 58, 1-10.

Piedra de la Cuadra, J., R. García Pérez, Á. Latorre Romero y C. Quiñones Delgado (2013). Género y Educación Física. Análisis de buenas prácticas coeducativas. Profesorado. Revista de Currículum y Formación del Profesorado, 17(1), 221-241.

Reinoso Castillo, I. y J. Hernández Martín (2011). La perspectiva de género en la educación. Cuadernos de Educación y Desarrollo, 3(28), 1-10.

Saraví, J. (1997). Género y formación docente en educación física. Educación Física y Deporte, 19(2), 29-36. 